Journal of Social and Development Sciences

Vol. 3, No. 6, pp. 214-222, June 2012 (ISSN 2221-1152)

\title{
Perceptions of Capacity Building among Youths Involved In Vocational Skills Development
}

\author{
Bede Obinna Amadi*, Haslinda Abdullah \\ Putra University, Malaysia \\ *bedeamadi@gmail.com
}

\begin{abstract}
As a way of tackling youth unemployment in Nigeria, the National Directorate of Employment provides capacity building in the form of vocational skills development for unemployed youths who lack skills in their areas of interest and are eager to acquire relevant skills. This paper examined the youths' perceptions of the components or dimensions of capacity building imparted in them. A structured survey questionnaire was used in collecting data to ascertain the levels of capacity building among the participants, while descriptive statistics was employed in analyzing the data. Findings from the study revealed that a greater percentage of the sampled youth reported high and moderate levels of their capacity building- implying that the vocational skills development was a successful scheme. It is however recommended that constraints that impede the success of the scheme be addressed by policy makers to make the outcome of the skills training more successful.
\end{abstract}

\section{Keywords: Capacity Building; Skill acquisition; Unemployment; National Directorate of Employment}

\section{Introduction}

The statistics from the Manpower Board and the Federal Bureau of Statistics has it that Nigeria has a youth population of 80 million, representing $60 \%$ of the total population of the country; with 64 million of them unemployed, while 1.6 million are underemployed (Awogbenle \& Iwuamadi, 2010). Among the causes of youth unemployment in Nigeria are rural-urban migration, rural underemployment and urban unemployment, lack of employable skills, rapid population growth, and absence of vibrant manufacturing sector. While these facts may not have captured in totality the youth unemployment scenario in Nigeria, they point to the fact that the situation is a very critical one. To address this menace, various regimes in Nigeria have initiated development programs geared towards self-employment and self-dependence among the youths. Agencies and institutions have been established with the mandate of combating unemployment and poverty facing the youths. One of these institutions is the National Directorate of Employment (NDE), established in 1986 (NDE, 2009). With the realization that one of the major causes of unemployment among the youth is lack of skills for wage employment or to become self-employed, the NDE designed the Vocational Skills Acquisition Training to train youths in a wide range of vocational skills in view of making them selfemployed and economically self reliant (NDE, 2009). The skill acquisition programs have been identified as panacea for the high youth unemployment, poverty and hunger in Nigeria, where statistics have shown that 70 per cent of the unemployed population of the country is unskilled (Ojei, 2010). Vocational skills development program equips youths with the human capital that let them avoid poverty and have a more fulfilling life. Investing such skills in them therefore calls for involvement of all stakeholders. The training involves the use of informal sector operators such as master craftsmen/women as training centers, where youths spend a period long enough for them to acquire the requisite skills. As Ojei (2010), the NDE coordinator explained, the training would empower the beneficiaries to become self-reliant; arguing that the youth could not continue to walk the streets looking for non-existent jobs; and that the training would lead to the creation of a new generation of self-employed youths who on their own would become employers of labor.

The training is a sustainable empowerment project of government focusing on youths to make them economically self reliant through vocational skills acquisition. The scheme is a shift from previous failed community development schemes, and its utmost objectives are to promote economic empowerment, selfemployment and self-reliance among unemployed Nigerian youth, as well as enhance their socio-economic 
wellbeing. Consequently, many Nigerian youths have benefitted from this scheme by going through the training. Some of the areas where they have been trained include Welding, Fabrication, Auto-Mechanic, Electrical Installation, Computer Operation, Catering, Fashion Designing, Hairdressing, Interior decoration, etc. Because of the skills they have acquired, youths are able to establish their individual businesses with the help of resettlement packages from NDE, bank credit facilities, and family support. The purpose of this paper is to examine the youths' perceptions of their skills training (or capacity building). This is done by examining the levels of response on the components of capacity building imparted in the youths. The components of capacity imparted in the youth as examined by the researcher are also reviewed to help elucidate the variables of the study. A review of relevant literature on how capacity building relates to empowerment is addressed. Next is the study's methodology, which is followed by the results and discussion of data. It is believed that the training will economically empower youths by making them self-employed, although the paper examined only the youths' perceptions of their skills training and not perceptions of their economic empowerment. Based on the responses of the participants, the paper offered some recommendations on how to enhance the training for optimum benefits for the youths.

\section{Literature Review}

Understanding Capacity Building: There are a variety of definitions and interpretations of the concept of capacity building depending on who uses it and in what context. Capacity development has been defined as the process by which individuals, organizations, institutions and societies develop abilities - both individually and collectively to perform functions, solve problems and set and achieve objectives (McGinty, 2002). Some definitions focus on the existence of commitments, skills, resources and problem solving abilities of the community, often as these are connected to a particular program or institution (Goodman et al., 1998). With regard to the many definitions of the concept, Chaskin, Brown, Venkatesh, and Vidal (2001) explain that capacity building can take place on the individual, organizational and community level; and that some capacity focus on affective connections and shared values, while others are concerned with processes of participation and engagement. They further talked about community capacity building, stressing those definitions of community capacity building focus on a range of dimensions and issues (Chaskin, Brown, Venkatesh, \& Vidal, 2001). Further, capacity building captures three main types of activity, namely:

- Developing skills - learning and training opportunities for individuals and groups, and sharing through networks and mutual support, to develop skills, knowledge and confidence.

- Developing structures - developing the organizational structures and strengths of community groups, communities of interest and networks.

- Developing support - developing the availability of practical support to enable the development of skills and structures (What is Capacity Building, n.d.).

Goodman et al. (1998) discuss some dimensions of capacity to include notions of participation and leadership, skills and resources, social and inter-organizational networks, sense of community and understanding of community history.

Capacity Building for Empowerment: Capacity building is an effective strategy for promoting empowerment. Slogans such as "helping people to help themselves" and the proverb, "teach a man to fish" point directly at capacity building. Capacity building is seen as a process by which individuals, groups and organizations, institutions and societies increase their abilities to perform core functions, solve problems and define and achieve objectives; to understand and deal with their development needs in a broad context and in a sustainable manner (UNDP, 1997). Eade (1997) sees it as an approach to development, which encompasses all the fields that influence the development sphere (Eade, 1997). Thus, it identifies the weaknesses that people experience in achieving their basic rights, and finding proper means through which to increase their ability to overcome the causes of their exclusion and suffering. Capacity building encompasses a strong process of learning and education. In addition, for capacity building to be sustainable, new technologies, new knowledge and information need to be introduced, especially in this period of information and communication technology. Capacity building is a comprehensive process that involves all dimensions of life. It is not so much a matter of just implementing a project or enhancing a particular aspect of life. It is an 
approach to development, which aims to enhance the capability of people in a comprehensive manner. As a people-centered activity, capacity building is a process of community development where people are the focus of capacity enhancement. It creates an enabling environment where people are developed in order to manage themselves and contribute to their societies. To this end, community development becomes the ultimate output of capacity building process. Thus, capacity building is a response to community development needs. On this understanding of capacity building as a process, Eade and Williams (1995) elaborate the concept as: Men and women becoming empowered to bring about positive changes in their lives; about personal growth together with public action; about both the process and the outcome of challenging poverty, oppression and discrimination; and about the realization of human potential through social and economic justice. Above all, it is about the process of transforming lives, and transforming societies (Eade \& Williams, 1995). In this process of capacity building, people acquire and improve their abilities. This creates an avenue for them as individuals and as members of the community to achieve their development objectives.

The Components of Capacity Building at a glance: The components or dimensions of capacity building, which were considered in this study for achieving economic empowerment among youths, include training, skill acquisition, personal growth initiative, perceived control, and self-esteem. While the standardized instruments used to measure some of these components have been used in previous studies and showed significant positive relationship with empowerment, perceived skill acquisition scale was developed by the researcher to measure participants' perception of skill acquisition. The five components are described below.

Training: The 'training' component was measured using the training satisfaction rating scale developed by Holgado-Tello, Moscoso, García, and Chaves (2006). It measures participants' training satisfaction, focusing on their experiences and appreciation of the training program they received. The authors measured the satisfaction of the Administrative and Service Personnel of the University of Seville's Training Center, to evaluate participants' reactions to training, about the training outcomes. Evaluation involved analyzing levels of satisfaction among participants with respect to various aspects of the training process. Other empirical studies on the relationship between training and empowerment have been widely reported in literature. For instance, training on agricultural innovation was identified as key factor for enhanced livelihood outcomes of rural smallholder farmers in Malawi (Mapila, Kirsten, \& Meyer 2011). Similarly, a study of impact of Information and Communication Technology (ICT) on rural Indian women showed that the women benefitted from the ICT training by way of access to new and improved information and new employment opportunities; thereby contributing to women empowerment (Rasheed-Sulaiman, Kalaivani, Mittal, \& Ramasundaram, 2011).

Skill acquisition: A skill is seen as ability to do something well, usually gained through training or experience. Skill acquisition on the other hand entails the earning of a new skill, or a way of doing things, usually gained through training or experience. According to Isaac (2011), effective engagement of youths in skill acquisition is an intervention mechanism in the eradication of unemployment and poverty in the society. For the current study, equipping the youths with useful skills is a key aspect of capacity building, aimed at economic empowerment and poverty reduction among youth. Youth are trained in a range of vocational and technical skills including welding, auto-mechanic, electrical installation, etc. The training not only equips them with the working tools to set up their own small-scale businesses and becoming self-employed and selfreliant, they are enabled with necessary skills that make them employers of labor. The skill acquisition in the study was measured using the perceived skill acquisition scale developed by the researcher. Participants responded to questions that accessed how they benefitted from the skills training and how the acquired skills have affected in their wellbeing.

Personal Growth Initiative: Robitschek (1998) defined personal growth initiative as "active, intentional, engagement in the process of personal growth" (p.184); and stated that this engagement encompasses, first, cognitions, which support and encourage personal growth (e.g., "I know how to change specific things that I want change in my life"); and second, behaviors, which actually exhibit these cognitions in behavior (e.g., "If I want to change something in my life, I initiate the transition process"). It implies, therefore, that people possessing high levels of personal growth initiative are conscious of the fact they have developed over time, and at the same time are intentionally seeking out personal growth experiences. Using the scale of personal 
growth initiative, Robitschek and Cook (1999) studied the Influence of Personal Growth Initiative and Coping Styles on Career Exploration and Vocational Identity of college students at a large southwestern U.S. university (p.131). The outcome was significant in the relationship between personal growth initiative and self-exploration as it showed that personal growth initiative predicted environmental exploration and vocational identity.

Perceived control: Perceived control is a personality trait that contributes to personal development. It is a robust predictor of success and resilience, such that people with higher perceived control show better performance. According to Skinner and Greene (2007) people who are confident and optimistic are more likely to "set high and concrete goals, deal productively with obstacles and setbacks, focus even under stress, seek help as needed, and rebound from failure." As a motivational characteristic, it is related to a variety of psychological responses, such as interest, curiosity, positive mood, and pride; and other positive behaviors, like persistence and effort exertion. However, the meaning of perceived control remains ambiguous because it is related to various theories such as Social Learning Theory, (Jacelon, 2007), self-efficacy and control in Social Cognitive Theory (Bandura, 1997), and Lifespan Theory of Control (Schulz \& Heckhausen, 1996). Perceived control also represents control beliefs for demands and resources in the framework of Person/Environment (Wallhagen \& Lacson, 1999). Economic empowerment has been associated in literature with perceived control. Parker (1993) believes that trusting that one has control, irrespective of the fact that the control may or may not be exercised can be psychologically beneficial and vital to wellbeing. Perceived control in the current study was merged with perceived competence, which is both subscales of the psychological empowerment scale developed by Menon (2001), to assess participants' level of perceived control and perceived competence in work related ability. In terms of the two subscales, an empowered individual is one who can say, "I have control over my work and work context", and "I have the personal competence to do my work" (p. 162). Empirical evidence lays credence to the positive relationship between levels of perceived control and empowerment, such as effects on task performance and job satisfaction (Greenberger, Strasser, Cummings, \& Dunham, 1989). Using Menon's scale, Luby (2006) investigated the perspectives of employees in a community college preparing for organizational change to examine their experiences that contributed to beliefs and behavioral expression of empowerment. One of the results of the study indicated that administrators and professionals had higher perceived control scores than did faculty and career service employees.

Self-esteem: Seen as a general feeling of self worth, self-esteem is identified as a cognitive predictor of empowerment because it shapes how individuals see themselves in relation to their work environments (Spreitzer, 1995). Through self-esteem, individuals feel possessing the required talents enough to impact in the work (Gist \& Mitchell, 1992). Individuals with high self-esteem are likely to extend their self-worth to a work-specific sense of competence. This is contrary to people possessing low self-esteem, who feel they do not have the right attitude to succeed, and are not likely to influence positively on their work (Spreitzer, 1995). Self-esteem, therefore, is related to Empowerment in the sense that it bestows in itself a feeling of "being able to do". The self-esteem concept has been widely adopted in several empirical studies. In a comparative study of professionally employed and nonprofessionally employed women in the city of Zabol of Iran, Azar and Vasudeva (2006) found that the former were higher on self-esteem than the later- a feeling that motivates them to contribute to the welfare of their families as well as society, and able to integrate their roles effectively as working women with their roles as wives and mothers. In a similar study, Park and Liao (2000) revealed that employed women in Korea have higher gratification, job satisfaction, and a feeling of worthiness than mere housewives who are not employed- an outcome credited to 'higher self-esteem' as the reason.

\section{Methodology}

The study employed a survey research design as a technique for data collection. According to Creswell (2003), survey design provides a quantitative or numeric description of perspectives or experiences or opinions of a population by studying a sample of that population. In addition, from the sample research, the researcher generalizes or makes claims of knowledge about the population. A simple random sampling technique was adopted in selecting a sample size of 268 from the population. Although Krejcie and Morgan 
(1970) recommended a sample size of 248 from a population size of 700, it is at the same time advised that since a high response in questionnaire survey is not always likely, a much higher number of questionnaires must be distributed if the researcher wants a targeted volume of responses (Self-administered Questionnaire, n.d.). Of the 268 participants who were surveyed, 250 questionnaires were returned, and subsequently analyzed- that is, two participants more than the number recommended by Krejcie and Morgan (1970). The study was conducted in the four area councils of Abuja, the Federal Capital Territory (FCT) of Nigeria, namely, Abuja Municipal, Gwagwalada, Kuje, and Bwari. Abuja has six area councils in all; the other two being Abaji and Kwali. The contact addresses of the respondents were provided by the training providers for access at their business locations. The researcher and his research assistant visited the respondents at those locations to administer the questionnaire. A period not exceeding one week was fixed and agreed upon for picking-up of the completed questionnaires. The data collected were analyzed using descriptive statistics to provide elaborate presentation of the data. Mouton (2001) stated that in analyzing the quantitative data, the descriptive statistics will be used to organize and summarize the data to render it more comprehensible. Descriptive statistics are used to present quantitative descriptions in a manageable form, describing what the data shows using tabular and graphical techniques. In other words, it provides simple summaries about the sample and the measures; and usually includes means, standard deviations, and frequencies. Frequencies are usually performed to calculate how many people answered each question with each response, and they provide the percentages or proportions for each frequency distribution (Anderson, MacLellan-Wright \& Barber, 2007).

\section{Results and Discussion}

The objective of this study was to examine the levels of capacity building among youths involved in vocational skill. In other words, perceptions of the youths on the various components of the skills training were investigated. Descriptive statistics was used to present the levels of participants' responses. Table 1 shows descriptive statistics for the five components of capacity building examined in the study.

Table 1: Descriptive Statistics for the Components of Capacity Building

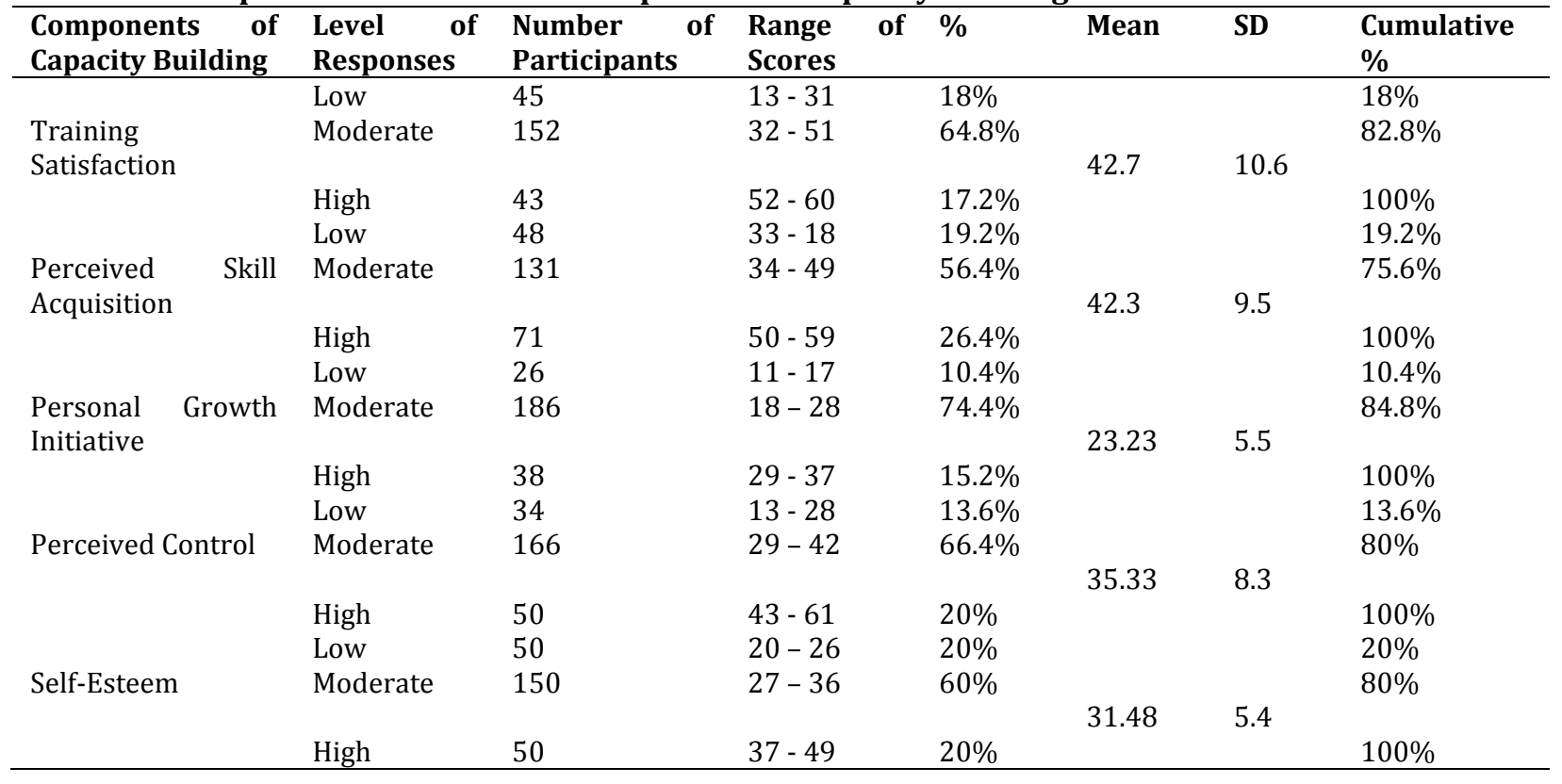

From the above table, the mean score on the Training satisfaction scale is 42.71 , a standard deviation of 10.617; a range of 47- minimum score of 13 and maximum score of 60. The mean score on the Perceived skill acquisition scale is 42.39 , a standard deviation of 9.513; a range of 41- minimum score of 18 and maximum score of 59. The mean score of the Personal Growth Initiative scale is 23.23, a standard deviation of 5.543; a range of 26- minimum score of 11 and maximum score of 37. The mean score of Perceived control is 35.33, a 
standard deviation of 8.272; a range of 48- minimum score of 13 and maximum score of 61 . The mean score of the Self Esteem scale is 31.48, a standard deviation 5.449; a range of 29-minimum score of 20 and maximum score of 49. In determining, the levels of participants' responses on the individual components of capacity building, responses were grouped in 'low', 'moderate', and 'high' levels. For training satisfaction, scores were categorized thus: For high level, scores one standard deviation above mean rating (42.71), that is, scores from 52 to 60 were categorized as high. For moderate level, participants' response total that range approximately within one standard deviation above and below the mean rating (42.71), that is, scores from 33 to 51 were categorized as moderate. For low level, scores approximately more than one standard deviation below mean rating, that is, scores from 13-31 were categorized as low. Table 2 below shows levels of participants' responses on Training Satisfaction scale.

Table 2: Levels of Participants' Responses on Training Satisfaction Scale

\begin{tabular}{lllll}
\hline Level & Number of Participants & Range of Scores & Percentage & Cumulative Percentage \\
\hline Low & 45 & $13-31$ & $18 \%$ & $18 \%$ \\
Moderate & 152 & $32-51$ & $64.8 \%$ & $82.8 \%$ \\
High & 43 & $52-60$ & $17.2 \%$ & $100 \%$ \\
Total & 250 & & $100 \%$ & \\
\hline
\end{tabular}

Table 2 highlights the levels of participants' responses on training satisfaction. 45 (18\%) of the participants reported a low level of training satisfaction; 152 (64.8\%) of the participants reported a moderate level of training satisfaction; while 43 of them reported a high level of training satisfaction. Secondly, to group the scores on perceived skill acquisition scale in categories the following was done: For high level, scores one standard deviation above mean rating (42.39), that is, scores from 50 to 59 were categorized as high. For moderate level, participants' response total that range approximately within one standard deviation above and below the mean rating (42.39), that is, scores from 34 to 50 were categorized as moderate. For low level, scores approximately more than one standard deviation below mean rating, that is, scores from 18 to 33 were categorized as low. Table 3 below shows levels of participants' responses on Perceived Skill Acquisition scale.

Table 3: Levels of Participants' Responses on Perceived Skill Acquisition Scale

\begin{tabular}{lllll}
\hline Level & Number of Participants & Range of Scores & Percentage & Cumulative Percentage \\
\hline Low & 48 & $18-33$ & $19.2 \%$ & $19.2 \%$ \\
Moderate & 131 & $34-49$ & $56.4 \%$ & $75.6 \%$ \\
High & 71 & $50-59$ & $26.4 \% \%$ & $100 \%$ \\
Total & 250 & & $100 \%$ & \\
\hline
\end{tabular}

Table 3 shows that majority of the participants reported moderate to high level of perceived skill acquisition. 131 (75.6\%) of them reported moderate level of skill acquisition; 71 (26.4\%) of them reported high level of skill acquisition; while 48 (19.2\%) of them reported low perceived skill acquisition. Third, to group the scores on personal growth initiative scale in categories or levels the following was done: For high level, scores one standard deviation above mean rating (23.23), that is, scores from 29 to 37 were categorized as high. For moderate level, participants' response total that range approximately within one standard deviation above and below the mean rating (23.23), that is, scores from 18 to 28 were categorized as moderate. For low level, scores approximately more than one standard deviation below mean rating, that is, scores from 11 to 17 were categorized as low. Table 4 below shows levels of participants' responses on Personal Growth Initiative scale.

Table 4: Levels of Participants' Responses on Personal Growth Initiative Scale

\begin{tabular}{lllll}
\hline Level & Number of Participants & Range of Scores & Percentage & Cumulative Percentage \\
\hline Low & 26 & $11-17$ & $10.4 \%$ & $10.4 \%$ \\
Moderate & 186 & $18-28$ & $74.4 \%$ & $84.8 \%$ \\
High & 38 & $29-37$ & $15.2 \%$ & $100 \%$ \\
Total & 250 & & $100 \%$ & \\
\hline
\end{tabular}


Table 4 shows that 186 (74.4\%) of the participants reported a moderate level of personal growth initiative; $26(10.4 \%)$ of them reported a low level of personal growth initiative; while 38 (15.2\%) of them reported a high level of personal growth initiative. Fourth, to group the scores on perceived control scale in categories or levels the following was done: For high level, scores one standard deviation above mean rating (35.33), that is, scores from 43 to 61 were categorized as high. For moderate level, participants' response total that range approximately within one standard deviation above and below the mean rating (35.33), that is, scores from 29 to 42 were categorized as moderate. For low level, scores approximately more than one standard deviation below mean rating, that is, scores from 13 to 28 were categorized as low. Table 5 below shows levels of participants' responses on Perceived Control scale.

Table 5: Levels of Participants' Responses on Perceived Control Scale

\begin{tabular}{lllll}
\hline Level & Number of Participants & Range of Scores & Percentage & Cumulative Percentage \\
\hline Low & 34 & $13-28$ & $13.6 \%$ & $13.6 \%$ \\
Moderate & 166 & $29-42$ & $66.4 \%$ & $80 \%$ \\
High & 50 & $43-61$ & $20 \%$ & $100 \%$ \\
Total & 250 & & $100 \%$ & \\
\hline
\end{tabular}

Table 5 shows that $66.4 \%$ (166) of the participants reported moderate perceived control; $13.6 \%$ (34) of them reported low perceived control; while 20\% (50) of them reported high-perceived control. To group the scores on self-esteem scale in categories or levels the following was done: For high level, scores one standard deviation above mean rating (31.48), that is, scores from 37 to 49 were categorized as high. For moderate level, participants' response total that range approximately within one standard deviation above and below the mean rating (35.33), that is, scores from 27 to 36 were categorized as moderate. For low level, scores approximately more than one standard deviation below mean rating, that is, scores from 20 to 26 were categorized as low. Table 6 below shows level of participants' responses on Self-Esteem scale.

Table 6: Levels of Participants' Responses on Self-Esteem Scale

\begin{tabular}{lllll}
\hline Level & Number of Participants & Range of Scores & Percentage & Cumulative Percentage \\
\hline Low & 50 & $20-26$ & $20 \%$ & $20 \%$ \\
Moderate & 150 & $27-36$ & $60 \%$ & $80 \%$ \\
High & 50 & $37-49$ & $20 \%$ & $100 \%$ \\
Total & 250 & & $100 \%$ & \\
\hline
\end{tabular}

Table 6 shows that majority (60\%) of the participants reported a moderate self-esteem. Fifty (20\%) of the participants reported high self-esteem, while fifty (20\%) also reported low self-esteem.

\section{Conclusion}

The study investigated youths who were involved in vocational skills development, designed to empower them economically. While many participants responded highly and moderately, some also reported a low level on the dimensions of capacity building. Overall, the responses indicate that largely the capacity-building program was a successful scheme. The study therefore has demonstrated that capacity building and the informal sector can be a source of hope for the unemployed Nigerian youth through skills training as they have proved to be a huge investment in the youth who could not be absorbed in the scarce or unavailable government employment. Based on the responses of the participants, the study has revealed that unemployment can be combated through capacity building. However, to make the scheme a more successful venture for the youth, it is recommended that government should identify with the youths in their training because it is through such partnership that they will identify and address the constraints that impede the vocational training program. Government should also encourage the informal sectors where these youths are trained by providing enabling environment and infrastructure so that the outcome of the training among the beneficiaries will be enhanced. Finally, while the study population was limited to a given sample size of participants who participated in the vocational skills development scheme, it is recommended that further research with a larger sample size be undertaken to confirm either fully or partly the findings of this study. 


\section{References}

Anderson, D., MacLellan-Wright, M. \& Barber, S. (2007). Analyzing Data Collected from the Community Capacity Building Tool: A Manual for Users: Public Health Agency of Canada.

Awogbenle, A. C. \& Iwuamadi, C. (2010). Youth unemployment: Entrepreneurship development program as an intervention mechanism. African Journal of Business Management, 4(6), 831-835.

Azar, A. S. \& Vasudeva, P. (2006). Self-Efficacy and Self-esteem: A Comparative Study of Employed and Unemployed Married Women in Iran. The German Journal of Psychiatry, 9, 111-117.

Bandura, A. (1997). Self-efficacy: The exercise of control. New York: Freeman.

Chaskin, R. J., Brown, P., Venkatesh, S. \& Vidal, A. (2001). Building community capacity. New York: Aldine De Gruyter.

Creswell, J. W. (2003). Research Design. London: Sage Publication.

Eade, D. (1997). Capacity Building: An Approach to People-Centered Development. Oxford: Oxfam Publications.

Eade, D. \& Williams, S. (1995). The Oxfam Handbook of Development and Relief. Oxford: Oxfam Publications.

Gist, M. E. \& Mitchell, T. R. (1992). Self-efficacy: A theoretical analysis of its determinants and malleability. Academy of Management Review, 17(2), 183-211.

Goodman, R., Speers, M., Mcleroy, K., Fawcett, S., Kegler, M., Parker, E. \& Wallerstein, N. (1998). Identifying and defining the dimensions of community capacity to provide a base for measurement. Health Education \& Behavior, 25(3), 258-278.

Greenberger, D. B., Strasser, S., Cummings, L. L. \& Dunham, R. B. (1989). The impact of personal control on performance and satisfaction. Organizational Behavior and Human Decision Processes, 43, 29-51.

Holgado-Tello, F. B., Moscoso, S. C., García, I. B. \& Chaves, S. S. (2006). Training Satisfaction Rating Scale: Development of a measurement model using polychoric correlations. European Journal of Psychological Assessment, 22(4), 268-279.

Isaac, N. (2011). Skills Acquisition, Tonic for Economic Empowerment. Leadership, 13.

Jacelon, C. S. (2007). Theoretical perspectives of perceived control in older adults: A selective review of the literature. Journal of Advanced Nursing, 59(1) 1-10.

Krejcie, R. V. \& Morgan, D. W. (1970). Determining Sample Size for Research Activities. Educational and Psychological Measurement, 30, 607-610.

Luby, C. E. (2006). A Case Study of Psychological Empowerment of Employees in a Community College. (Doctoral Dissertation). Retrieved from ProQuest Dissertations and Theses. (UMI No. 3224579).

Mapila, M. A., Kirsten, J. F. \& Meyer, F. H. (2011). Agricultural rural innovation and improved livelihood outcomes in Africa. Retrieved from http://www.csae.ox.ac.uk/conferences/2011-EDiA/papers/017Mapila.pdf.

McGinty, S. (2002). Community Capacity Building. Paper presented at the Australian Association for Research in Education Conference, Brisbane, QLD.

Menon, S. T. (2001). Employee Empowerment: An Integrative Psychological Approach. Applied Psychology: An International Review, 50(1), 153-180.

Mouton, J. (2001). How to succeed in your master's and doctoral studies. A South African guide and resource book. Pretoria: Van Schaik.

National Directorate of Employment. (2009). Annual Report. Abuja: Author.

Ojei, B. (2010). NDE Registers 320 for Skill Acquisition in Enugu. Retrieved from http://www.nigerianbestforum.com/generaltopics/?p=42339.

Park, J. \& Liao, T. F. (2000). The Effect of Multiple Roles of South Korean Married Women Professors: Role Changes and the Factors, Which Influence Potential Role Gratification and Strain. Sex Roles, 43(7/8), 571-591.

Parker, L. E. (1993). When to fix it and when to leave Relationships among Perceived Control, Self-efficacy, Dissent, and Exit. Journal of Applied Psychology, 76(6), 949-959.

Rasheed-Sulaiman, V., Kalaivani, N. J., Mittal, N. \& Ramasundaram, P. (2011). ICTs and Empowerment of Indian Rural Women: What can we learn from on-going initiatives? (CRISP Working Paper 2011-001 ed.). Hyderabad: Centre for Research on Innovation and Science Policy.

Robitschek, C. (1998). Personal Growth Initiative: The Construct and its Measure. Measurement and Evaluation in Counseling and Development, 30(4), 183-198. 
Robitschek, C. \& Cook, S. W. (1999). The Influence of Personal Growth Initiative and Coping Styles on Career Exploration and Vocational Identity. Journal of Vocational Behavior, 54(1), 127-141.

Schulz, R. \& Heckhausen, J. (1996). A life-span model of successful aging. American Psychologist, 51(7), 702714.

Self-administered Questionnaire. (n.d.). Retrieved from http://medanth.wikispaces.com/Selfadministered+Questionnaire.

Skinner, E. \& Greene, T. (2007). Perceived control: Engagement, coping, and development. In T. L. Good (Ed.), 21st century education: A reference handbook. Newbury Park: Sage.

Spreitzer, G. M. (1995). Psychological empowerment in the workplace: Dimensions, Measurement, and Validation. Academy of Management Journal, 38(5), 1442-1465.

UNDP. (1997). Capacity Development and UNDP: Supporting Sustainable Human Development. New York: UNDP.

Wallhagen, M. I. \& Lacson, M. (1999). Perceived Control and Psychosocial/Physiological functioning in African American elders with Type 2 Diabetes. The Diabetes Educator, 25(4), 568-575.

What is Capacity Building? (n.d.). Retrieved http://www.ccwa.org.uk/v2/downloads/cms/1121303664.pdf. 